\title{
The Effects of Forage Policy on Feed Costs in Korea
}

\author{
Jae Bong Chang \\ Department of Food Marketing and Safety, Konkuk University, Seoul 05029, Korea; jbchang@konkuk.ac.kr; \\ Tel.: +82-2-2049-6010
}

Received: 30 April 2018; Accepted: 27 May 2018; Published: 29 May 2018

\begin{abstract}
Feeding operations are substantial on livestock farms, besides being potentially expensive. Feeding efficiency has been considered a major influence on profits in the livestock industry. Indeed, feed costs are shown to be the largest single item of production cost in Korea. To promote production and use of domestic forage, the Korean government has enforced the forage base expansion program that strengthens the competitiveness of the livestock industry by reducing the production cost. The forage base expansion program includes three main policies: subsidized forage production, support for processing and distribution, and expanding land for forage production. This paper investigates the influence of the government's policies often conjectured to have pronounced effects on forage production. To evaluate the forage policies, this paper uses a path-analysis approach linking government spending on forage base expansion programs and feed costs. Results indicate that the Korean government's spending on supporting domestic forage production results in a decrease in the ratio of forage expenses to total feed cost.
\end{abstract}

Keywords: feed costs; forage production; path analysis; policy

\section{Introduction}

Many countries are highly dependent on feed imports and, in general, feed is the largest part of production costs. For example, Korea imports $75 \%$ of its compound feed and $96.4 \%$ of its feed crops, which has become a matter of concern among Korean livestock industry participants and the Korean government [1]. Feed is the most significant cost in livestock production, often representing more than half of the production costs. Indeed, the portion of feed cost for Hanwoo (Korean beef cattle) and dairy cattle are $38 \%$ and $58 \%$ of the total cost to produce beef, respectively [2]. Thus, the price of international crops and the surge in feed prices related to oil prices directly affect domestic livestock farms.

The livestock industry contributes more than $40 \%$ of the total value of agricultural output in Korea. From the beginning of 1990 to 2016, consumption of meat in Korea increased by 1.7 million tons. During the same period, per-capita meat consumption increased from $19.9 \mathrm{~kg}$ to $49.5 \mathrm{~kg}$ [3]. Rising domestic consumption has been an important factor in stimulating import demand, resulting in the self-sufficiency of meat production decreasing from $90.0 \%$ to $68.0 \%$. Furthermore, the beef self-sufficiency rate is much lower than total meat, and it recorded $41 \%$ in 2016.

There has been a trend towards fewer livestock farms with large numbers of animals to achieve economies of scale. For instance, the average number of Hanwoo and dairy cattle per farm in 2017 was 31.6, which is about 10 times that of 1990. As of 2017, Korea had a total of 3.0 million beef cattle and 409,000 dairy cows.

Making a small change in the quantity of the type of feed has a greater impact on profitability than any other cost due to its large impact on production costs. To operate stable animal husbandry and production management, producing high-quality forage can reduce feed costs and create an import substitution effect. As a result, the Korean Ministry of Agriculture, Food and Rural Affairs (MAFRA) has implemented the forage base expansion program in 1998 to expand the production base for domestic forage and to utilize resources. 
The forage base expansion program includes three main policies: subsidized forage production, support for processing and distribution of forage, and expanding land for forage production. Firstly, the vast majority of spending on the program, 65 percent, is allocated to forage production subsidies such as the silage production, forage seed, and equipment and machine. For instance, the Korean government supports the cost of silage production by $60,000 \mathrm{KRW} /$ ton (US\$50.72/ton based on the exchange rate of $1182.91 \mathrm{KRW} / \mathrm{US} \$$ on January 2017). Secondly, the regional hub and distribution center or total mixed ration (TMR) suppliers are supported to allow efficient supply of raw materials. In 2017, the Korean government spent a total of 45 billion KRW on supporting the processing and distribution facilities for forage production. Thirdly, the government creates and expands the specialized zone for forage production by subsidizing raw materials such as silage, seed, equipment, machinery and compost.

Although there have been many arguments on the merits of supporting domestic forage production, relatively little empirical work has investigated the effects of this program. In general, policies and regulations can affect domestic forage production directly or indirectly. Since one of the primary issues associated with forage policy is identifying how this public program affects the livestock industry in Korea, it is important to determine how the forage production expansion policy affects domestic forage production and how this domestically produced forage impacts feed costs. Thus, the purpose of this article is to examine the effects of the aforementioned policy to support domestic forage production. This study uses a path-analysis model linking government spending on the forage base expansion program to feed costs, and disaggregates the effects to different stages. The results of this study might provide insight into the process of forage policy influencing feed costs in Korea and initial information to support better understanding for adaptive strategies by other countries.

\section{Materials and Methods}

\subsection{Path Analysis}

To accomplish the research objectives, the hypothesized relationship between government spending on expanding domestic forage production and feed costs was examined using a path-analysis approach. Path analysis refers to a variety of statistical techniques that aim to represent the directed dependencies among a set of observable variables and to test the causal interactions among variables [4]. The advantage of a path analysis over regression is that it concurrently performs multiple regression analyses while it produces an overall assessment of the fit of the model, usually based on a $\chi^{2}$ statistic [5]. This type of so-called sequential multiple regression model is widely used in policy analysis [6,7] and has been discussed in detail by authors such as Dye and Pollack [8], Edwards and Lambert [9], and Pedhazur [10].

This study builds on the simple path model, focuses on forage-related policy, and links government spending with feed costs. More specifically, the share of forage feed cost in total feed costs is a dependent variable and the exogenous independent variable is expenditure on forage production. The assumption is that there are only three endogenous independent variables, the domestic forage production, forage imports, and head of beef cattle. The primary focus is on how the policy related to the use of government spending might affect the livestock industry associated with feed costs, rather than on methodological or theoretical issues. Thus, for this study, the path model was estimated using three main sets of maximum likelihood estimation equations in the CALIS SAS procedure, as shown in Figure 1. The CALIS procedure uses a variety of modeling languages to fit structural equation models. The first set explored the relationship between government spending (Budget) in year $t$ as an independent variable, and domestic forage production (Domestic) in year $t$ and forage imports (Imports) in year $t$ as dependent variables, and these are given by the Equation (1).

$$
\text { Domestic }_{t}=\alpha_{0} \text { Budget }_{t}+e 1_{t} \text {, and Import } \text { I }_{t}=\alpha_{1} \text { Budget }_{t}+e 2_{t},
$$


where $e_{t}$ are the error terms. The second set, in which the head of beef cattle (Cattle) in year $t$ was the dependent variable, included forage imports and domestic forage production as independent variables, and is expressed as the Equation (2).

$$
\text { Cattle }_{t}=\beta_{0} \text { Domestic }_{t}+\beta_{1} \text { Import }_{t}+e 3_{t}
$$

In the last step, the head of beef cattle is the basic factor influencing the share of forage feed costs in the total feed costs (Share_Fcost). Besides, the path model defined the share of forage feed cost as the dependent variable, and public spending as well as the domestic forage production, forage imports, and the head of beef cattle as independent variables. The path model for the share of forage feed costs is shown as the Equation (3).

$$
\text { Share_Fcost } t_{t}=\gamma_{0} \text { Budget }_{t}+\gamma_{1} \text { Domestic }_{t}+\gamma_{2} \text { Import }_{t}+\gamma_{3} \text { Cattle }_{t}+e 4_{t}
$$

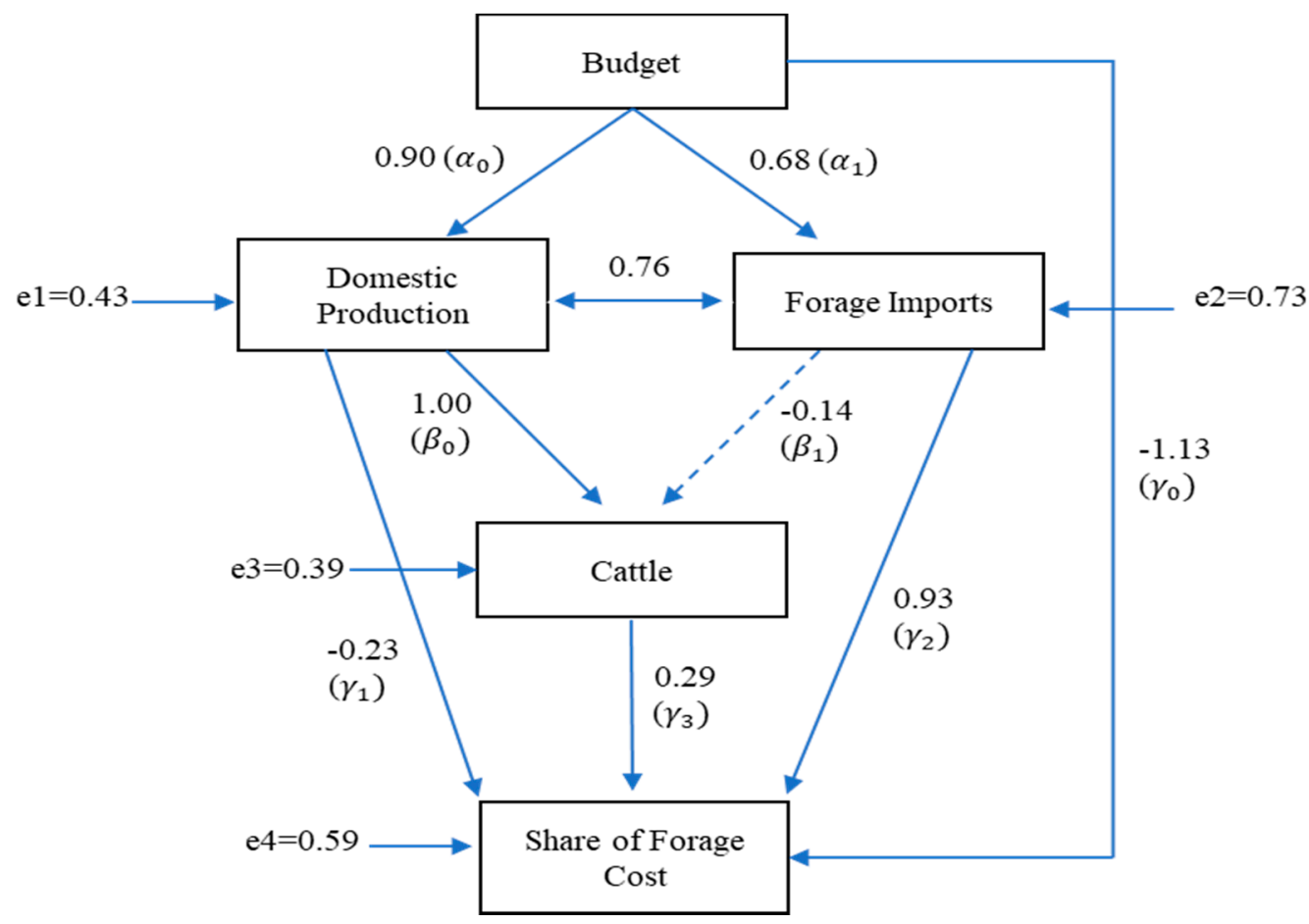

Figure 1. Path-analysis diagram for how feed cost is affected by government spending on domestic forage production in Korea, from 1998 to 2016. All the lines in the diagram represent a specific linear model. Solid lines indicate good evidence for an effect ( $95 \%$ or higher significance), and dotted lines indicate no clear relationship.

\subsection{Data}

Table 1 shows the descriptions of all variables and the descriptive statistics for path analysis. Data on the budget for expanding forage production by the government are inferred from the MAFRA spending on the forage base expansion program over the years 1998 to 2016 . Over time, total government costs have trended upward and recorded an annual growth rate of $9.9 \%$ during this period. Total government costs of the forage base expansion program in 2016 were 118,997 million KRW. Driven in part by the increase in government spending on the forage base expansion program, domestic forage production increased annually, by 1.5\%, from 1998 to 2016 . While domestic forage production increased, this change remained below the eighteen-year historical average increase of $13.4 \%$ in forage imports. The annual growth rates of head of beef cattle, feed costs and forage feed costs were $1.2 \%, 6.6 \%$ and $7.3 \%$ respectively. 
Table 1. Descriptive statistics for forage and beef cattle industry in Korea: 1998-2016.

\begin{tabular}{ccccccc}
\hline Variable & Descriptions & Mean & $\begin{array}{c}\text { Standard } \\
\text { Deviation }\end{array}$ & Min. & Max. & $\begin{array}{c}\text { Annual } \\
\text { Growth Rate }\end{array}$ \\
\hline Budget & $\begin{array}{c}\text { Annual government } \\
\text { spending on the forage } \\
\text { base expansion program in } \\
\text { 1 million KRW }\end{array}$ & $68,348.1$ & $50,444.8$ & 15,600 & 157,707 & $9.9 \%$ \\
\hline Domestic & $\begin{array}{c}\text { Domestic forage } \\
\text { production in 1000 tons }\end{array}$ & 3859.4 & 590.9 & 2793 & 4672 & $1.5 \%$ \\
\hline Import & Forage import in 1000 tons & 795.1 & 259.4 & 172 & 1120 & $13.4 \%$ \\
\hline Cattle & $\begin{array}{c}\text { Number of beef cattle } \\
\text { heads in 1000s }\end{array}$ & 2262.8 & 578.0 & 1406 & 3059 & $1.2 \%$ \\
\hline Cost & $\begin{array}{c}\text { Annual feed cost per head } \\
\text { in KRW }\end{array}$ & $1,832,697.8$ & $862,191.6$ & 803,038 & $2,982,290$ & $6.6 \%$ \\
\hline Fcost & $\begin{array}{c}\text { Annual cost for forage per } \\
\text { head in KRW }\end{array}$ & $282,637.0$ & $123,665.4$ & 114,257 & 452,739 & $7.3 \%$ \\
\hline
\end{tabular}

Source, Ministry of Agriculture, Food and Rural Affairs (2017), Statistics Korea (2017).

\section{Results}

The results from the estimated path model are reported in Table 2 (and also Figure 1). These coefficient values can also be observed in Figure 1. Estimates associated with variables can be interpreted as the relative strength and a sign of the causal effect to outcome variables. With only one exception, all parameter estimates were statistically significant and carried the expected signs. In addition, the goodness-of-fit index of 0.91 indicates a reasonably good fit of the path model, and a chi-squared value of 4.8313 with two degrees of freedom yields a $p$-value of greater than 0.05 . Thus, the path model is not rejected.

The government spending $\left(\alpha_{0}=0.903\right)$ had a positive direct effect on expanding domestic forage production. The results also present that domestic forage production $\left(\beta_{0}=0.997\right)$ had a positive effect on the number of beef cattle herds. The explanatory variables accounted for $85 \%$ of the variance in explaining health behaviors. In addition, in the final model, government spending $\left(\gamma_{0}=-1.128\right)$ and domestic forage production $\left(\gamma_{1}=-0.225\right)$ had a negative effect, while beef cattle herds $\left(\gamma_{3}=0.291\right)$ and forage imports $\left(\gamma_{4}=0.930\right)$ had a positive effect on the share of the forage cost to the total feed cost. The model variables accounted for $65 \%$ of the variance of the share of forage cost in the total feed cost.

Table 2. Path model estimates.

\begin{tabular}{cccccc}
\hline Outcome & $\boldsymbol{R}^{\mathbf{2}}$ & Variable & Coefficients & Standard Error & $p$-Value \\
\hline Share_Fcost & 0.65 & Budget & -1.128 & 0.027 & $<0.001$ \\
& & Cattle & 0.291 & 0.038 & $<0.001$ \\
& & Domestic & -0.225 & 0.022 & $<0.001$ \\
Cattle & 0.85 & Import & 0.930 & 0.017 & $<0.001$ \\
& & Domestic & 0.997 & 0.064 & $<0.001$ \\
Domestic & 0.82 & Import & -0.135 & 0.117 & 0.248 \\
Import & 0.47 & Budget & 0.903 & 0.019 & $<0.001$ \\
& & & 0.682 & 0.092 & $<0.001$ \\
\hline
\end{tabular}

Government expenditure toward expanding forage production had a significant impact on domestic forage production, which in turn decreased the share of forage cost in the total feed cost. The Pearson correlation (0.76) shows that the domestic forage production correlates to forage imports positively. It is worth emphasizing the difference in the estimated effects of domestic forage production and imports to the forage total feed-cost ratio of beef cattle, which presumably reflects underlying 
differences in the feed costs implied by the two different forage feeds. It also implies that the two forage feeds are substitutes.

The direct and indirect effects of government intervention are summarized in Table 3. The results indicated that government expenditure had the largest direct effect on the share of forage cost in total feed costs. Apart from the direct effect on the forage feed costs ratio, government expenditure had a positive indirect effect on the share of forage feed costs through their impacts on forage imports and the number of beef cattle. Domestic forage production was found to lower the share of forage cost in total feed costs.

Table 3. Estimated direct and indirect effects of government spending and domestic forage production on cost share of forage in the path analysis model.

\begin{tabular}{cccc}
\hline Factors of the Share of Forage Cost & Direct Effect & Indirect Effect & Total Effect \\
\hline Budget & $-1.128^{* *}$ & $0.667^{* *}$ & $-0.462^{* *}$ \\
& $(0.082)$ & $(0.204)$ & $(0.123)$ \\
Domestic & $-0.225^{* *}$ & $0.291^{* *}$ & $0.065^{*}$ \\
& $(0.022)$ & $(0.052)$ & $(0.036)$ \\
\hline
\end{tabular}

Significance level: ${ }^{* *} p$-value $<0.05 .{ }^{*} p$-value $<0.10$; numbers in parentheses ( ) are standard error.

\section{Discussion}

Livestock production costs are gaining attention in the public and private sectors in Korea. In Korean livestock farming, the self-sufficient feed ratio has declined each year and the high level of feed imports has increased production costs. There are several reasons for the decreased or stagnant self-sufficiency ratio in Korea. Because the primary arable land use is for crop, mainly rice, production, there is high competition with crops and livestock. This must necessarily lead to replacement of one by the other, or specialization. Furthermore, livestock farmers in Korea tend to consider the quality of imported forage better than locally produced forage. Environmental factors such as temperatures, precipitation or location are the fundamental factors influencing the forage quality. However, four seasons in Korea do not always allow forage to achieve the equal levels of quality. Another reason might be related to the increase in the scale of livestock and rice production. Where the average farm size has increased, mechanized and specialized farming systems have become dominant, and these depend on concentrated and imported forage feed for livestock farming.

As a result, several production cost-reduction initiatives have emerged in recent years and the Korean MAFRA has already been moving toward implementing some of these policies, particularly policy solutions toward reducing feed costs. For example, the forage base expansion program that encourages domestic forage production of import-substituting forage has been implemented since 1998. Spending on supporting domestic forage production varies from year to year, but it has hovered around 120 billion KRW (US\$ 100 million) in recent years (note that average exchange rate for Korean won (KRW) to USD in 2016 was 1 USD = 1160.50 KRW (Bank of Korea)). Despite the fact that, on average, public spending for domestic forage production has been increasing, the impact of this government intervention remains unclear. While the primary aim of the forage production policy is to boost domestic products, it also induces reducing feed cost.

Applying the path-analysis model, the effects of government spending on the domestic forage base expansion program and the share of forage feed costs were examined. The public spending on domestic forage production is directly (positively) related to the expansion of domestic forage production, which is consistent with findings from a previous study [11], and in turn, aims to decrease the share of forage feed costs. Ahn and Han [11] indicated that Korea's forage self-sufficiency rate would remain about 56 percent with no government support. Despite this effect, there is not enough of a substitution effect between imported and domestically produced forage. As total spending for the forage expansion program by the government has trended upward over time, domestically produced forage product has increased but has averaged only 1.5 percent per year for the past eighteen years. 
However, on average, the annual growth rate of imports has been as high as $13.4 \%, 11.9$ percentage points higher than the $1.5 \%$ annual domestic production growth rate over the corresponding period. Thus, since 2010, Korea's forage self-sufficiency has remained fairly stable each year at approximately 80 percent.

According to a MAFRA report [12], on average, prices of domestic forage were about $14.3 \%$ lower on a dry-matter basis than the price of import forage, which is mainly caused by shipping and handling costs. In addition, rice has been the most valuable crop and constitutes a major source of farm income in Korea. However, with the change of Korean diet and eating habits, per-capita annual rice consumption showed a continuously decreasing trend. To address this issue, the Korean government began a program which aims to change cropping systems for paddy fields with food or forage crops alternative to rice.

Korean livestock farmers will be more unprosperous when Korea further opens its agricultural markets to competitors all over the world by having freer trade. Ensuring a flow of efficiency-enhancing animal husbandry is a mechanism to improve farmer and livestock industry wellbeing. Economic and environmental goals are important, and many can be reached through government policies that are encouraging farms to convert from food to feed, providing subsidies for both the growing forage as well as to their purchases by beef and dairy cattle industries and in more local ways.

Conflicts of Interest: The author declares no conflict of interest.

\section{References}

1. Sung, M.H.; Yoon, J. Status of Feedstuffs Imports and Calculation of Import Price Index; Korea Rural Economic Institute: Seoul, Korea, 2013.

2. Statistics Korea. Livestock Production Cost Survey Report 2016; Statistics Korea: Seoul, Korea, 2017.

3. Korean Ministry of Agriculture, Food and Rural Affairs. Statistics of Agriculture, Livestock and Food 2017; Ministry of Agriculture, Food and Rural Affairs: Sejong, Korea, 2017.

4. Smith, A.F.; Brown, H.J.; Valone, J.T. Path analysis: A critical evaluation using long-term experimental data. Am. Nat. 1997, 149, 29-42. [CrossRef]

5. Singh, J.; Wilkes, R.E. When consumers complain: A path analysis of the key antecedents of consumer complaint response estimates. J. Acad. Mark. Sci. 1996, 24, 350-365. [CrossRef]

6. Defourny, J.; Thorbecke, E. Structural path analysis and multiplier decomposition within a social accounting matrix framework. Econ. J. 1984, 94, 111-136. [CrossRef]

7. Erdag, C. Accountability policies at schools: A study of path analysis. Educ. Sci. Theor. Pract. 2017, 17, 1405-1432. [CrossRef]

8. Dye, T.R.; Pollack, N.F. Path analytic models in policy research. Policy Stud. J. 1973, 2, 123-130. [CrossRef]

9. Edwards, J.R.; Lambert, L.S. Methods for integrating moderation and mediation: A general analytical framework using moderate path analysis. Psychol. Methods 2007, 12, 1-22. [CrossRef] [PubMed]

10. Pedhazur, E.J. Multiple Regression in Behavioral Research, 3rd ed.; Cengage Learning: New York, NY, USA, 1997; p. 1072, ISBN 9780030728310.

11. Ahn, B.I.; Han, S.H. Analysis on the effects of government's support for forage production. Korean J. Agric. Econ. 2016, 57, 55-78.

12. Korean Ministry of Agriculture, Food and Rural Affairs. Demonstration of Harvesting Grass Feed, Promoting Production and Utilization. Available online: http:/ / www.korea.kr/common/download.do? fileId=184244049\&tblKey=GMN (accessed on 11 May 2016).

(C) 2018 by the author. Licensee MDPI, Basel, Switzerland. This article is an open access article distributed under the terms and conditions of the Creative Commons Attribution (CC BY) license (http://creativecommons.org/licenses/by/4.0/). 